\title{
El dermatólogo y su papel ante la pandemia por SARS-CoV-2: COVID-19
}

\author{
The dermatologist and his role in the SARS-CoV-2 pandemic: COVID-19
}

Patricia Alfaro Ledesma*

Citar como: Alfaro LP. El dermatólogo y su papel ante la pandemia por SARS-CoV-2: COVID-19. Acta Med Grupo Angeles. 2021; 19 (s1): s7-s8. https://dx.doi.org/10.35366/101022

A partir de la aparición de la humanidad, hemos tenido que resistir y desarrollar inmunidad contra numerosas infecciones, tanto bacterianas, por ejemplo el cólera, la peste bubónica, o el meningococo, entre otras, y virales, como la viruela, el sarampión, el ébola, SARS, MERS, la influenza española e influenza H1N1.

La mayoría de estos padecimientos presentan lesiones cutáneas características, las cuales en general son causadas por la bacteria o el virus, aunque en ocasiones son el resultado de la respuesta inflamatoria del huésped o de los medicamentos.

Los coronavirus probablemente estén en el ambiente desde que el ser humano apareció sobre la tierra, se cree que desde el año 3300 a. C. sus reservorios eran animales y las descripciones de enfermedades humanas son casi inexistentes. Sin embargo, muchos malestares atribuibles a estos virus aparecieron alrededor de 1960, en pequeños brotes. Esto ha motivado su estudio exhaustivo, pues siendo los virus RNA, podrían utilizarse en la fabricación de nuevos antivirales y vacunas.

Durante la última década del siglo XX y la primera del XXI, varios brotes epidémicos provocados por la familia de los orthocoronaviridae han sido registrados: SARS-CoV-1 y MERS fueron las últimas, causando alteraciones respiratorias de alta diseminación y mortalidad, que en aquel momento pudieron aislarse a tiempo.

A partir de que la Segunda Guerra Mundial llegó a su fin, las generaciones posteriores nunca habíamos vivido algo tan catastrófico como esta pandemia. Un virus altamente

\footnotetext{
* Dermatóloga, Hospital Ángeles Pedregal, Ciudad de México.

Correspondencia:

Patricia Alfaro Ledesma

Correo electrónico: alfaroledesma@yahoo.com.mx

www.medigraphic.com/actamedica

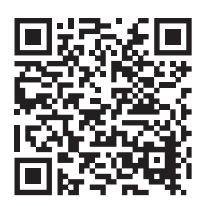

infeccioso, el cual no sólo afecta las vías respiratorias, sino que produce una enfermedad sistémica. Nos tomó por sorpresa a todos, puso al planeta de cabeza ya que, debido a la globalización y al desplazamiento intensivo de muchísimas personas, se propagó como un tsunami a los cinco continentes y produjo la saturación de muchos sistemas de salud, los cuales se vieron rebasados por la cantidad de enfermos graves, quienes requerían asistencia ventilatoria en unidades de cuidados intensivos.

Además de desconocer la naturaleza y el comportamiento del trastorno, el arsenal farmacéutico antiviral con el cual se contaba fue inútil, los escasos estudios sobre otras medicinas que podrían combatirlo limitaron su uso y la vacuna eficaz se volvió un anhelo. Estamos viendo a una humanidad desprotegida ante una amenaza biológica, y por el momento sobrevivir es la meta.

Era esperado que esta infección produjera también daños en la piel: exantemas predominantemente, pero desconocíamos cuán frecuentes serían, si revelarían algún signo o síntoma específico, cuál sería su papel en la historia natural de la misma y si poseerían algún factor pronóstico.

Al principio, para los dermatólogos fue muy desconcertante, pues la información llegada desde China no hablaba de afección de la piel. Reportes anecdóticos fueron surgiendo en la literatura a medida que el contagio se fue esparciendo. Tuvimos que esperar a que la piel expresara esos signos. Fue el grupo del Dr. Recalcati en Italia el que empezó a describir diversas lesiones cutáneas. Posteriormente los españoles, encabezados por Galván Casas, reunieron 375 casos, lo cual permitió que tales deterioros pudieran ser clasificados en cuanto a su morfología, presentación y duración en relación a la historia natural del padecimiento.

La reclusión prolongada de la población, el miedo de los enfermos a acudir a sus consultorios o a laboratorios, el alto costo de múltiples estudios de diagnóstico, y la limitación para ingresar a las unidades COVID-19 implementadas en 
los hospitales públicos y privados, han evitado que conozcamos realmente la frecuencia con la cual se presentan en nuestra población.

La piel no parece ser uno de los órganos "blanco" preferidos del virus, en la literatura mundial se han publicado aproximadamente 1,000 casos bien documentados asociados a la infección, lo cual es bajo, partiendo de que hasta el momento en que se escribió este documento, la cifra de infectados era superior a 35 millones; es posible que sean muchos más, pues no todos dan pruebas de PCR, lgM o IgG positivas, aún con cuadros muy sugestivos de la enfermedad.

Para cuando el padecimiento se empezó a diseminar en México, ya sabíamos qué tipo de laceraciones íbamos a encontrar y empezamos a buscarlas en forma intencional, a diagnosticarlas por medio de las redes sociales y por telemedicina. No estábamos habituados a trabajar por estos medios, ha sido complejo hacer consultas eficaces en forma digital o telefónica, dado que no se puede observar a los pacientes en forma integral, revisar sus mucosas, palpar las lesiones, hemos trabajado con iconografía muy deficiente, ya que muchos pacientes estaban encerrados solos y no podían tomar adecuadas fotografías de sus lesiones. Por otro lado, a fin de hacer diagnósticos diferenciales, se requería de estudios de laboratorio e histopatología que no podían hacerse a domicilio. Recordemos que los exantemas virales son muy parecidos entre sí y las reacciones a medicamentos pueden jugar un papel preponderante.

Además, hemos visto y tratado las consecuencias de las medidas preventivas y del uso del equipo de protección que el personal de salud ha requerido, tratando de evitar la infección. La reclusión de la población en casa ha provocado aumento de contacto con sus mascotas, favoreciendo infecciones e infestaciones, brotes de enfermedades preexistentes al igual que condiciones asociadas al estrés. Muchos de nuestros pacientes suspendieron sus tratamientos o se automedicaron, y ahora nos enfrentamos a cuadros más severos que requieren de atención inmediata.
Los dermatólogos, al igual que otros especialistas, hemos necesitado implementar medidas para protección de nosotros mismos, de nuestro personal y de nuestros enfermos, disminuyendo el número de citas, de asientos en la sala de espera, educando al paciente sobre los riesgos de contagio y del cuidado de su propio padecimiento, lo mismo que de aquellos problemas que tendrán si suspenden su tratamiento.

Sabemos que nunca volveremos a ser los mismos. Los daños causados por este germen serán incalculables. ¿Cómo es que un minúsculo microrganismo pudo ser capaz de alterar así nuestras vidas, nuestros planes y proyectos? Ahora tendremos que convivir con una nueva enfermedad que nos ha enseñado que somos vulnerables.

La pandemia nos ha dejado dolorosas enseñanzas: que los científicos podemos contradecirnos todos los días, que deberíamos saber discernir en cuanto a la información que leemos y lo que vemos en la realidad, que debemos estar atentos a nuestros pacientes y aprender de ellos, pues son los mejores maestros, que hemos de confiar en nuestra intuición y que ser médico es una profesión de alto riesgo que nadie nos protegerá; nosotros tendríamos que hacernos responsables de evitar la infección para no transmitirla a los enfermos, compañeros de trabajo o familiares.

Nuestro compromiso es seguir observando, leyendo, discriminando y aplicar los nuevos conocimientos en beneficio de dichos pacientes.

Por último, y no menos importante, es imperativo unirnos como médicos en defensa de nuestro gremio, que por mucho ha sido el más golpeado por la pandemia y reconocer a nuestros compañeros quienes perdieron la vida al luchar en la primera línea de atención de los contagiados de COVID-19.

Conflicto de intereses: La autora declara no tener conflicto de intereses en esta publicación. 